\title{
Geruststelling en goede uitleg kan patiënten al erg helpen"
}

Jozien Wijkhuijs, Joost van der Gulden

Vlak na de eerste coronagolf heeft het Radboudumc een Corona Nazorgpoli opgericht. Daar werken artsen vanuit verschillende disciplines met andere hulpverleners samen om mensen te helpen die klachten houden na een corona-infectie, maar ook om te onderzoeken wat de effecten zijn van zo'n infectie. TBV spreekt longarts Jeanine Antons, klinisch psycholoog Jan Vercoulen en klinisch arbeidsgeneeskundige Theo Senden over hun werkzaamheden bij deze bijzondere poli.

Alle mensen uit de regio Nijmegen die zijn opgenomen in het ziekenhuis met COVID-19 worden uitgenodigd op de Radboudumc Corona Nazorgpoli. Die ligt in een groene, bosrijke omgeving in Groesbeek, op locatie Dekkerswald.

\section{'Ons behandeladvies verschilt per patiënt}

\section{omdat de problematiek die we aantreffen}

\section{buitengewoon heterogeen is'}

Ook mensen die thuis ziek zijn geweest kunnen door hun huisarts worden doorverwezen naar de poli, als ze na drie maanden nog steeds klachten hebben.

Klinisch psycholoog Jan Vercoulen werkt bij de afdeling medische psychologie, maar is sinds 25 jaar ook gedetacheerd bij de afdeling longziekten en longrevalidatie. De aanpak van de polikliniek is duidelijk nodig, zo blijkt uit het feit dat IC-arts en (inmiddels) televisiepersoonlijkheid Diederik Gommers onlangs in zijn podcast nog opriep tot meer samenwerking tussen disciplines bij corona nazorg. "Wij doen dit al sinds mei, juni vorig jaar", zegt Vercoulen. "De Corona Nazorgpoli is een multidisciplinaire poli, waar in ieder geval de longarts, verpleegkundig specialist en de fysiotherapeut bij betrokken zijn en afhankelijk van hun triage haken andere disciplines aan. Zo nodig ziet de geriater ook mensen op de poli en is de internist betrokken bij multidisciplinair overleg."

"Volgens mij zijn wij de enigen die het op dit moment al zo doen", vertelt hij. "Er zijn allerlei initiatieven, maar de manier waarop wij de nazorg georganiseerd hebben ken ik verder niet." Dit is volgens hem ook niet zo verwonderlijk, want in het Radboudumc is veel ervaring met multidisciplinaire assessments. "De longrevalidatie hebben wij ook zo georganiseerd. Dat we vanaf het begin breed inzetten is heel uniek, niet alleen in Nederland, maar in de hele wereld."

\section{Heterogene problematiek}

Als psycholoog participeert Vercoulen met fysieke gesprekken na triage op basis van vragenlijsten. "Daarmee meten we de klachten zoals moeheid, pijn en benauwdheid, kwaliteit van leven, beperking door klachten in het dagelijks leven, angst, PTSS en cognitieve problemen." Daarna volgt een behandeladvies op maat in samenspraak met andere disciplines. "Die verschilt per patiënt, omdat de problematiek die we aantreffen buitengewoon heterogeen is." Op basis van de eerste onderzoeken blijkt wel dat veel patiënten ernstige beperkingen ervaren in het dagelijks leven. Ook rapporteert ruim een kwart van de patiënten cognitieve problemen, al zie je dat na testen met een cognitieve prestatietaak maar bij 10 procent van de gevallen terug, vertelt Vercoulen.

Ook longarts Jeanine Antons is betrokken bij deze polikliniek. Zij legt allereerst iets uit over de twee verschillende groepen patiënten. "We begonnen met het actief oproepen van COVID19-patiënten die opgenomen zijn geweest in het Radboudumc, zowel op de verpleegafdeling als op de intensive care. Al heel snel voor de zomer van 2020 bleek echter dat er onder patiënten die thuis ziek waren geweest ook een grote behoefte bestond om gezien te worden." Daarom werd de poli in het najaar ook voor die groep opengesteld. "Er zit natuurlijk wel een verschil tussen die groepen. De eerste groep werd opgeroepen 


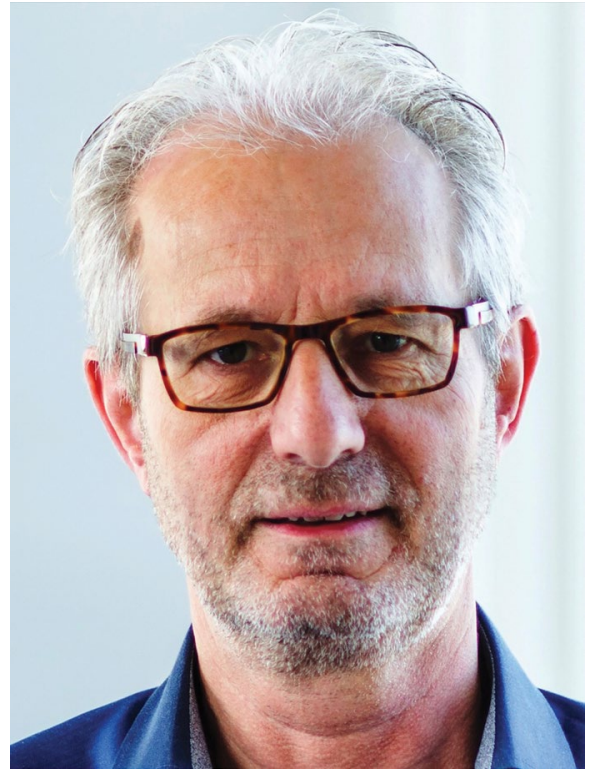

Theo Senden

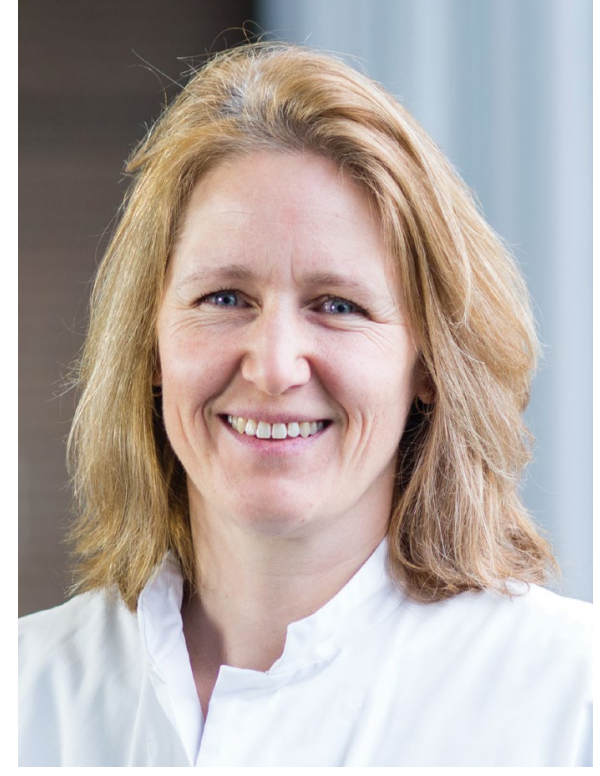

Jeanine Antons

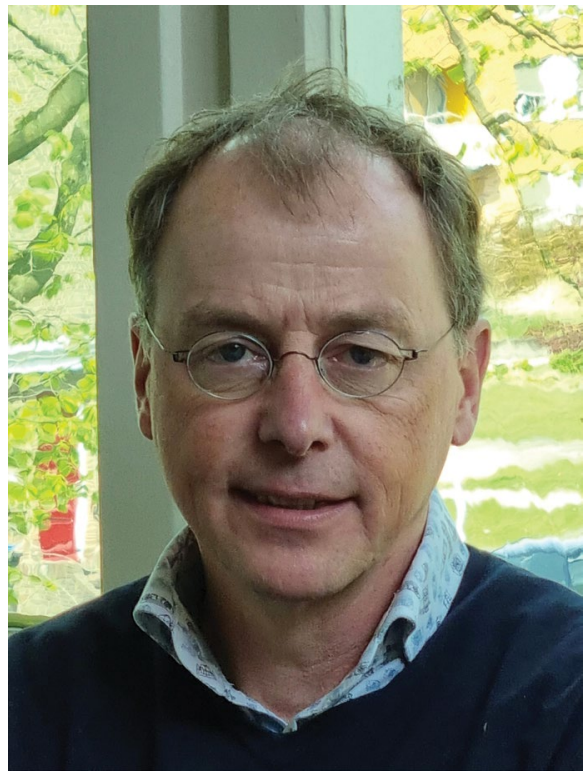

Jan Vercoulen ongeacht hoe ze hersteld zijn en de tweede groep werd doorverwezen door de huisarts vanwege klachten." Volgens Antons was de aanvankelijke gedachte dat COVID-19 vooral zou leiden tot blijvende longschade. "Vanwege de uitgebreidheid van de longbeelden die we zien bij een acute infectie, met matglasafwijkingen in beide longen. Daarbovenop komen langdurige IC-trajecten met buikbeademing of mensen die met zuurstofbehoefte op de verpleegafdeling liggen", vertelt ze. "Maar in het afgelopen jaar is eigenlijk gebleken dat het aantal gevallen van blijvende longschade niet zo groot is." Een subgroep, met name mensen die op de IC hebben gelegen, blijft diffusiestoornissen en problemen met zuurstofopname houden. En de groep die door de huisarts werd verwezen houdt soms lang last van hoest of dyspneuklachten en vermoeidheid. "Verder zijn er nog niet-respiratoire klachten zoals aanhoudend reuk- of smaakverlies, concentratieproblemen, geheugenproblemen of pijnklachten. En wat we ook veel zien is een geobjectiveerde spierzwakte.

\section{'Een groot deel van de problemen komt}

\section{voort uit niet-objectiveerbare oorzaken'}

De kracht in de bovenbeenspieren is bijvoorbeeld bij veel mensen meetbaar verlaagd."

\section{Geruststelling}

Vaak is het zoeken naar objectiveerbare of meetbare medische oorzaken, zegt Antons. "Soms vragen we ook of de cardioloog of neuroloog meekijkt, bijvoorbeeld.” Maar een groot deel van de problemen komt voort uit niet-medische oorzaken. Over het algemeen komen de artsen van de Nazorgpoli dan al heel ver door mensen gerust te stellen. "Patiënten zijn vaak op zoek naar informatie en antwoorden. Als je dan diagnostiek hebt gedaan en je combineert dat met goede uitleg en geruststelling, kan dat al erg helpen."

Theo Senden, klinisch arbeidsgeneeskundige, bevestigt wat Vercoulen en Antons zeggen. "Er is veel diversiteit in klachten en problematiek. Waar mensen in het werkveld echter vooral tegenaan lopen, is toch die inspanningsintolerantie en beperkte belastbaarheid", vertelt hij. Ademdysregulatie, zelfs in relatieve rust, lijkt daar vaak een rol bij te spelen. Als hij dit vervolgens verder uitvraagt, is er bij veel mensen vooral sprake van energiegebrek en een verhoogde herstelbehoefte. "Mensen gaan dan vaak te lang door en putten zichzelf zo uit dat ze daarna twee dagen moeten bijkomen. Daardoor raken sommigen helemaal het kompas kwijt, ze weten niet meer waar ze staan." Volgens Senden is dit vooral verwarrend voor mensen die eigenlijk helemaal niet zo heel erg ziek zijn geweest. "Die denken vaak al snel dat ze moeten doen alsof er niets aan de hand is en gaan zichzelf dan forceren. Dan zie ik mensen die eigenlijk al een heel eind zijn met re-integreren en dan toch weer helemaal tot 0 terugvallen omdat ze zichzelf hebben uitgeput. Daarna komen ze dan maar weer moeilijk op gang."

\section{Herstellen vraagt geduld}

In het begin van de coronacrisis, toen er nog veel onduidelijk was, was er veel begrip en ruimte bij werkgevers voor mensen die met een corona-infectie thuis kwamen te zitten. "Afhankelijk van het krediet dat iemand heeft, wordt het geduld en begrip op een gegeven moment minder, zien we", vertelt Senden. "Met name de afgelopen twee maanden zie ik steeds vaker mensen die inmiddels ongeveer een jaar ziek zijn en dan onder 
druk komen te staan. Dan gaan er bij de werkgever allerlei alarmbellen rinkelen en ontstaat er druk om tot een oplossing te komen. Denk aan een arbeidsdeskundig onderzoek voor een 'UWV-proof dossier' of plannen voor re-integratie tweede spoor. Mensen zijn soms nog maar nauwelijks aan het re-integreren in hun eigen werk en raken hierdoor in paniek. Er ontstaat zo soms een hele dynamiek die enorm veel onrust en stress geeft en daarom averechts werkt, omdat mensen al beperkt belastbaar zijn."

Jan Vercoulen herkent wat Senden hier beschrijft, vertelt hij. "Wat mensen vergeten is dat, als het gaat om beperkte belastbaarheid, die beperking zich uit in alles wat er in 24 uur gebeurt, niet alleen in werk, maar ook thuis." Zo ziet hij de laatste tijd veel vrouwen met jonge kinderen, die vastlopen. "Dan putten ze zich al uit op het werk, komen ze thuis, dan lukt al helemaal niets meer. Dat gaat frustreren. Vaak worden die problemen erger naarmate de tijd vordert."

Wat hierbij volgens Senden ook een rol speelt, is het eigen referentiekader van de patiënt. "Ik zie bijvoorbeeld patiënten die eerst vijf keer per week sportactiviteiten deden en die geen enkele belemmering ervoeren in hun leven. Die zeggen nu dat ze helemaal niets meer kunnen. Dat kun je ook relativeren door te stellen dat 'niets meer kunnen' hier relatief is ten opzichte van wat iemand eerst deed", zegt hij. In zo'n geval is het belangrijk om eerst een paar stappen terug te zetten voordat iemand weer vooruit probeert te komen.

Theo Senden communiceert deze noodzaak tot afremmen ook met de eigen bedrijfsartsen van patiënten die hij ziet.

\section{Meer informatie}

Jan Vercoulen schreef mee aan Comprehensive health assessment three months after recovery from acute COVID-19, waarin de eerste patiënten op de Nazorgpoli worden beschreven. Dit artikel is online te vinden.

C-support, een organisatie voor COVID-nazorg, publiceerde het rapport De eerste indrukken Covid-19 patiënten met langdurige klachten (zie www.c-support.nu). Wat opvalt is dat $56 \%$ in de eerste golf niet is getest. Dit wreekt zich nu zij bijna een jaar of langer ziek zijn. Het maakt erkenning voor hun klachten een stuk lastiger.

Interessant is ook COVID-19 en arbeidsgerelateerde zorg. 14 vragen en antwoorden voor arboprofessionals (zie www.beroepsziekten.nl) en de Algemene handreiking COVID-19 (zie www.ser.nl). Meer informatie is ook te vinden op www.radboudumc.nl/ projecten/arbeidsgerichte-zorg.
"Het is helpend om die mee te nemen in wat er met de patiënt is gebeurd op de poli en wat de uitkomst van de screening is", zegt hij. "Hierbij benadruk ik vaak dat het zaak is om niet te hard van stapel te lopen en eerder af te remmen dan gas te geven, zodat alle activiteiten gestroomlijnd verlopen, zowel op het werk als in het privéleven." Er is al een handreiking om bedrijfsartsen te helpen bij het zien van cliënten, zegt hij. "Maar dat is allemaal nog wel heel globaal. De beoordeling blijft lastig. Het gaat er toch vooral om dat je een beeld vormt van de persoon die je voor je hebt met zijn cognities en copingstijl. Maar ook van de factoren in de privé- en werkomgeving die het herstel en de re-integratie kunnen belemmeren. En dat je samen met diegene onderzoekt aan welke 'knoppen gedraaid kan worden' om herstel en re-integratie te bevorderen en niet te belemmeren. Gaat diegene niet al te hard in het re-integreren en spelen er geen belemmerende factoren?" Senden vertelt dat de klinisch arbeidsgeneeskundigen in het behandelteam veel verwachten van multidisciplinaire revalidatie voor de groep die grote problemen heeft met re-integratie in werk wegens problemen met adaptatie,

\section{'Mensen voelen zich serieus}

\section{genomen, ze zijn gescreend en er zijn dingen uitgesloten'}

coping en verstandige conditie-opbouw. "In het ziekenhuis hebben we die niks te bieden, omdat ze over het algemeen geen echte longproblematiek hebben. In de eerste lijn is er wel de mogelijkheid van de zogenaamde Herstelzorg via de zorgverzekering, maar dat is ongecoördineerde revalidatiezorg van monodisciplines naast of na elkaar."

\section{Acceptatie en adaptatie}

Antons vertelt dat de artsen bij de Nazorgpoli kiezen voor een revalidatie-insteek in plaats van een behandeling. Daarmee bedoelt ze dat ze de klachten nemen zoals ze zijn, uitgaan van de bestaande situatie en van daaruit kijken naar hoe iemand zijn leven weer kan oppakken. "Bij veel chronische aandoeningen kijk je naar de nieuwe eindsituatie, maar dat doen wij dus niet. Wij gaan uit van het gegeven dat die klachten zijn zoals ze zijn en we zoeken samen met de patiënt naar wat we kunnen verbeteren in de nabije toekomst." Dit komt mede doordat we als internationale medische gemeenschap nog niet weten of deze klachten blijvend zijn, dat moet nog maar blijken, stelt ze. "Uiteindelijk hopen we natuurlijk dat we in de toekomst een verklaring krijgen vanuit wat ik het biomedische model noem, maar dat hebben we vooralsnog nog niet." Volgens Antons begint het traject wel met een grondige screening op dat biomedische gebied. "We onderzoeken 
heel goed wat de somatische verklaringen zijn voor de klachten", vertelt ze. "Dan kun je daarna samen met de patiënt verder praten over de interactie tussen alle factoren die spelen. Onze ervaring tot nu toe is dat mensen hier heel erg voor openstaan." Theo Senden vult aan: "De grote waarde van onze insteek is dat mensen het gevoel hebben dat ze serieus zijn genomen, ze zijn gescreend en er zijn dingen uitgesloten. Hierdoor blijven niet steeds dezelfde vragen terugkomen in het hele traject." Wat volgens hem ook niet mag worden overgeslagen, is het gesprek over acceptatie en adaptatie. "Die stap wordt nog weleens overgeslagen, het accepteren van je verminderde belastbaarheid en nadenken over hoe je omgaat met je klachten zodat je niet je eigen herstel in de weg zit."

\section{'De behandeling bij de Nazorgpoli is zeer}

\section{gevarieerd en individueel'}

Jan Vercoulen stelt dat het werk dat wordt gedaan op de Nazorgpoli ook met preventie te maken heeft. "We hebben al veel kennis gehaald uit onze eigen onderzoeken naar het chronische vermoeidheidssyndroom, uit de jaren 90. Wij meten waar mensen hun klachten aan toeschrijven." Mensen die nog maar relatief kort klachten hebben, ervaren weinig weerstand tegen uitleg over niet-somatische factoren, zoals gedragsfactoren en andere psychologische factoren. Later, als mensen al jaren klachten hebben, neemt die weerstand toe en zoeken ze veel vaker een verklaring in het somatische spoor. "Wij zoomen daar eerst op in en hebben er aandacht voor. Daarna leggen we alles duidelijk uit en op die manier kunnen we chroniciteit en somatiseren voorkomen. Dan blijft er natuurlijk nog een groep over die zich helemaal vastbijt in het somatische spoor, maar die is relatief klein." Antons bevestigt dit. "Je kunt zo heel goed aan mensen uitleggen dat alle lichamelijke voorwaarden voor herstel aanwezig zijn. Dan kunnen ze verder met wat bijvoorbeeld Jan en Theo te bieden hebben."

\section{Behandeling op maat}

De behandeling die de Nazorgpoli aan patiënten indiceert is zeer uiteenlopend en individueel. Vercoulen geeft een voorbeeld van iemand die hij onlangs zag. "Een mevrouw die verpleegkundige is en op een familiefeestje besmet raakte, samen met haar man, ouders, zwangere dochter, een zwager, enzovoorts. Binnen een paar weken overleden haar beide ouders en ook een paar van haar eigen patiënten, die ze tijdens haar werk had besmet", vertelt hij. "Je kunt je voorstellen dat deze mevrouw vooral met rouwverwerkingsproblematiek en schuldgevoelens zit." Daar kwam bij dat ze als verpleegkundige werkte en altijd maar door wilde. "Dus hebben we fysiotherapie en ergotherapie ingeschakeld om haar activiteitenpatroon beter te stroomlijnen en daar hoort dan ook een verwijzing voor psychotherapie bij voor de verwerking."

Ook zien de therapeuten een grote groep jonge mensen of mensen van middelbare leeftijd die altijd heel sportief waren en dan merken dat dat niet meer lukt. "Dan hebben we natuurlijk in de fysiotherapeuten uit de eerste lijn heel goede partners, deels voor training, maar ook voor coaching," vertelt Antons. "Ze moeten mensen soms echt afremmen, mensen willen zo snel mogelijk weer op hun oude niveau terugkomen, maar dat is niet altijd de realiteit."

Voor verzekeringsartsen is deze problematiek ook nog weinig vertrouwd, zegt Senden, omdat er nog geen patiënten zijn die twee jaar ziek zijn. De verzekeringsartsen zien alleen nog patiënten die voor het ziektewetspreekuur komen. "Ook daar is het belangrijk om rustig weer op te bouwen. Dat de verzekeringsarts niet zomaar op grond van een globaal oordeel bepaalt dat iemand 50 of 100 procent geschikt is en moet gaan solliciteren, zodat ze meteen weer volle bak aan de slag moeten. Dan kun je voorspellen dat het fout gaat." De kunst voor patiënten is de dag, in samenspraak met hun bedrijfs- of verzekeringsarts, zo in te richten dat ze 's avonds denken dat zij best nog iets hadden kunnen doen, stelt Senden. "Als je de dag afsluit zonder energieschuld, dan heb je het goed gedaan. Dat zijn dingen die mensen snappen, het geeft houvast en begrip. Mensen kunnen er op deze manier zelf iets aan doen en er weer grip op krijgen." 